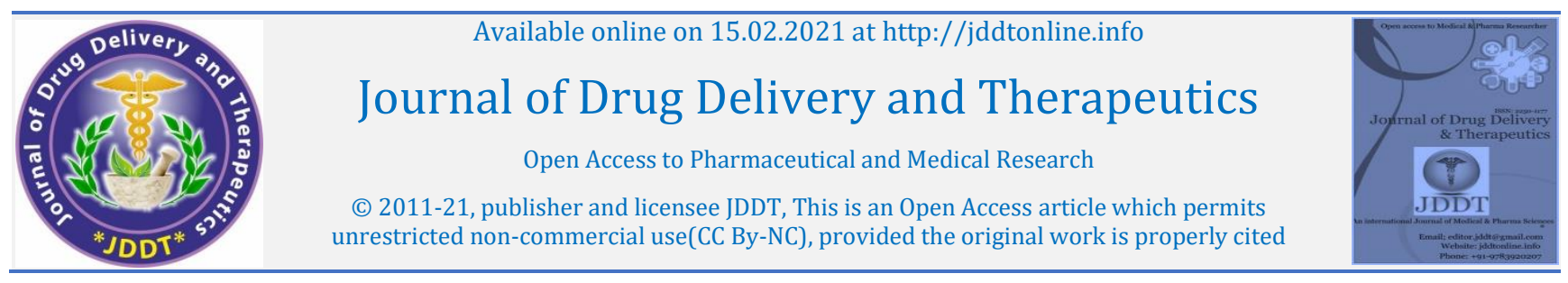

Open Access Full Text Article

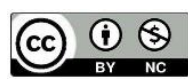

Review Article

\title{
A Review on Gastro-Retentive Floating Microspheres
}

\author{
Anuradha A. Birajdar*1, Madhuri T. Deshmukh², Rajkumar V. Shete ${ }^{3}$ \\ ${ }^{1}$ M Pharm. Student, Department of Pharmaceutics, Rajgad Dnyanpeeth's College of Pharmacy, Bhor-412206 Dist-Pune, (M.S) India \\ 2 Professor, Department of Pharmaceutics, Rajgad Dnyanpeeth's College of Pharmacy, Bhor-412206 Dist-Pune, (M.S) India \\ ${ }^{3}$ Principal, Department of Pharmacology, Rajgad Dnyanpeeth's College of Pharmacy, Bhor-412206 Dist-Pune, (M.S) India
}

\begin{tabular}{l}
\hline Article Info: \\
\hline Article History: \\
Received 21 Nov 2020; \\
Review Completed 11 Jan 2021 \\
Accepted 19 Jan 2021; \\
Available online 15 Feb 2021
\end{tabular}

Cite this article as:

Birajdar AA, Deshmukh MT, Shete RV, A Review on Gastro-Retentive Floating Microspheres,

Journal of Drug Delivery and Therapeutics. 2021;

11(1-s):131-138

DOI: http://dx.doi.org/10.22270/jddt.v11i1-s.4518

\section{Abstract}

The floating microsphere's purpose is to improve gastric retention time. Floating drug delivery systems are lower in bulk thickness than gastric juice and remain floating on gastric juice for a long period of time without impacting the gastric-emptying rate and increasing bioavailability. Gastro-retentive microspheres are particularly suitable for the continuous or late release of oral formulations with blending versatility to achieve various release patterns, low dose risk as a reproducible and short gastric retention time. The aim of this review is to address literature on the floating device, techniques, selection of suitable or inappropriate drug candidates for GRDDS, low density polymers used to swim over gastric fluid, processes, and floating microsphere assessment and application.

Keywords: GRDDS, Floating system, Approaches, Polymer, Mechanism, Methods

\section{*Address for Correspondence:}

Ms. Anuradha A. Birajdar, M Pharm. Student, Department of Pharmaceutics, Rajgad Dnyanpeeth's College of Pharmacy, Bhor-412206 DistPune, (M.S) India

\section{INTRODUCTION}

The most popular method for the administration of medication is the oral route. The traditional delivery system of medicines only appreciates and retains the concentration of medicines within the therapeutically active range when taken many times a day, depending on the dosage regimen. The outcome indicates a major fluctuation in the amount of medication. Tactics to solve these traditional fluctuations contributed to the advancement of several NDDS. The aim of all drug delivery systems is to provide the satisfying concentrations in the body with a therapeutic amount of medication at a particular location. Floating drug delivery is intended to hold the drug in the stomach \& ideal for drugs with poor solubility \& low intestinal fluid stability on the basis that FDDS makes the dosage type less dense than gastric fluid to allow it swim on them. Without impacting the rate of gastric emptying. Drugs with shorter half-lives that are readily absorbed in GIT are highly removed from the circulation of the serum. To resolve these difficulties, the oral managed drug delivery mechanism has risen as they release the drug into the GIT for longer periods of time and retain a steady concentration of medication in the serum. In the gastric area, gastroretentive dosage type may last for few hours and thus significantly increase the drug GRT to improve bioavailability, minimize drug waste and improve the solubility of drugs with low solubility. Floating microspheres are empty spherical particles without a center, in a strict sense. With free-flowing particles ranging in size from 1 to $1000 \mu \mathrm{m}^{1,2,34}$.

\section{FLOATING SYSTEM}

The method of floating drug delivery has a bulk thickness of less than GI fluid and therefore lasts for a prolonged duration of buoyancy in the abdomen without impacting the rate of gastric emptying. The material floats in this process, then it is delayed to release the material from the system at the critical rate after release of the drug. This raises the risk of bacterial invasion of the body and results in good control of bacterial drug concentrations ${ }^{3,5}$.

\section{Classification of Floating delivery of drugs \\ Effervescent system}

The production of carbon dioxide bubbles in this system allows the medication to swim. This includes carbonate or bicarbonate that reacts to the natural acid in the stomach or tartaric acid that contributes to the formation of carbon dioxide 2,6

\section{Volatile device containing liquid}

A deformable device that stretches from the collapsed position and then returns from the extended position to the collapsed position to maximize the drug's delivery time is included in this method. 


\section{Device producing Gas}

In this system, when reacting to the acid environment, the medium is added to bicarbonate material, contributing to the formation of carbon dioxide, thus reducing their bulk thickness and helping them swim over the GI fluid.

\section{Non-effervescent system}

As the drug is swallowed in this system, it reacts with gastric fluids and swells, thus reducing its bulk thickness and then swimming over the gastric fluid.7,8,9,10.

1. System of Micro Porous Compartment

2. Micro-Balloon Floating

3. Barrier colloidal gel device

4. Beads Alginate

\section{Micro Porous System for Compartments}

In this, the medication is put within the porous micro compartment along its bottom and top wall with pores. The air is trapped by the floatation chamber and then the gastric fluids start to float.

\section{Micro-Balloon Floating}

They are made of lightweight concrete or synthetic form and are hollow glass in nature.

\section{Barrier colloidal gel device}

There is a hydro-colloidal gel shape in this system that allows the medication to stay swimming on the gastric material.

\section{Beads Alginate}

This generation of calcium alginate precipitate is prepared by lowering sodium alginate into an aqueous solution of calcium chloride. It contributes to the development of the porous system, which enables it to float over the gastric fluid for more than 12 hours.

\section{Method of Raft Forming (in situ gel formation)}

A gel forming polysaccharide, polymer solution swells it and forms viscous consistent gel trapped with co2 bubbles that generates a raft layer on top of gastric fluid, so conveniences slowly release medication in the belly 6

\section{Floating Device Method to Gastric Retention}

A number of principles are shown in Fig.1 using a range of techniques to enhance stomach retention of dosage type. These methods are:

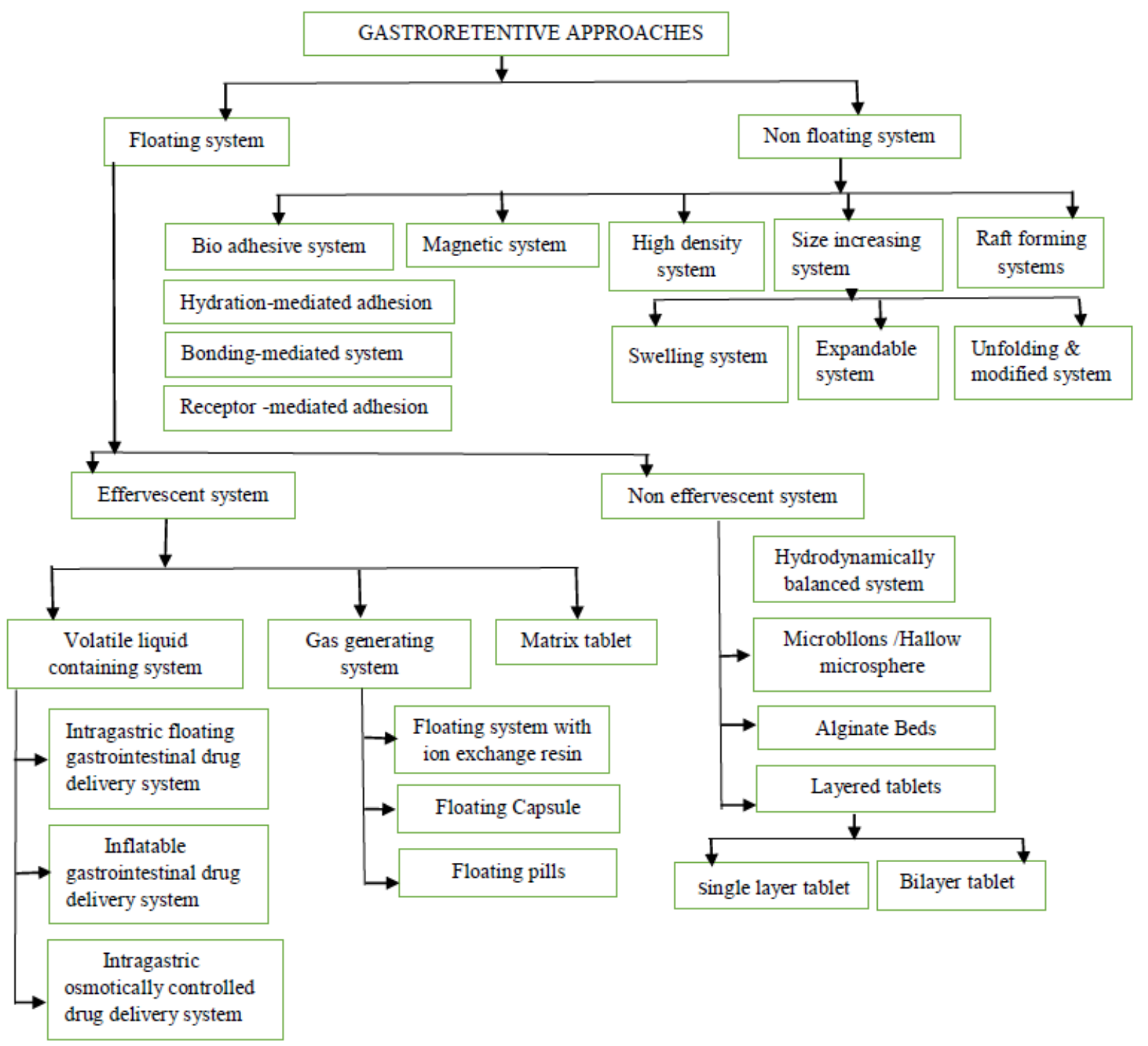



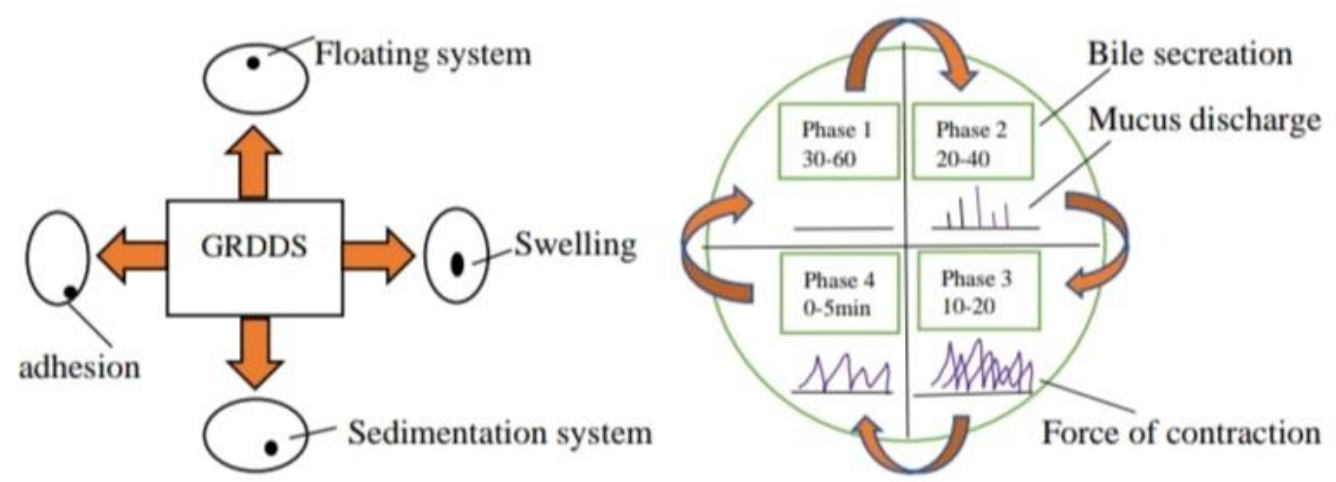

Figure 1: Approaches of gastric retention

\section{Latest Gastro Retention Combination Approach 11}

1. Floating and Swellable

2. Floating and Bioadhesive

3. Bioadhesion and elevated density

4. Pulsatile-floating

\section{Potential drug candidate for delivery of gastro-retentive} medication 12

1. Medicine in the GI tract with a short absorption window, e.g. with furosemide.

2. Medicines in the stomach work locally, e.g. Antacids, ulcerresistant medications, etc.

3. Medication Consumed mainly from the abdomen and upper portion of the GIT, e.g. calcium supplements.

4. Breakdown of drugs in the colon, such as ranitidine $\mathrm{HCl}$, metronidazole, etc.

5. A medication that disrupts normal colonic bacteria, e.g. trihydrate amoxicillin.

6. A substance that has poor solubility at high pH levels. E.g. diazepam.

A medicine that is not appropriate for the delivery of gastro-retentive drugs 12

1. Medicines with very limited solubility of acids, e.g. phenytoin.

2. Medicinal products that suffer from gastric instability, such as erythromycin.

3. Suggested medication for selective colon release, e.g. corticosteroids.

\section{Factors that affect the duration of gastro-retention 16}

1. Density: Lower gastric material density will swim across the surface while high density settles towards the bottom of the abdomen. Floating activity requires a density of $<1 \mathrm{gm} /$ $\mathrm{cm}^{3}$.

2. Size \& Shape: Size should be more than $7.5 \mathrm{~mm}$ in diameter \& shape show of good property associated with other shapes is either circular or spherical shaped dosage type.

3. Age \& Gender: There is more GRT in geriatric patients and less GRT in neonates and more GRT in children \& males than in females.

4. Multiple unit formulation: This was needed because of the release profile of the prophecy.
5. Posture: GRT is capable of varying between the patient's supine and upright steady states,

6. Fed or Unfed State: Due to the increase in gastric motility, GRT is lower during fasting.

7. Nature of the meal: Due to changes in gastric motility, high levels of fatty acids and other indigestible polymers which are slow down the GRT.

8. Feed frequency: Low migratory myoelectric complex frequency gives GRT, which in turn depends on the frequency of food intake.

9. Caloric Content: A high diet rich in protein and fat will increase GRT by 4 to 10 hours.

10. Disease State: Gastric diseases such as diabetes, chronic disease, hypothyroidism, hyperthyroidism, GRT alteration of duodenal ulcers, etc.

11. Concomitant drug intake: GRT is affected by the combination of many medications with gastric motility enhancers or depressants.

\section{Floating Microsphere Advantages}

$>$ Increasing the bioavailability of drugs

$>$ Site-specific medication delivery

$>$ Enhanced biotransformation of first-pass

$>$ Give long-term therapeutic effects

$>$ Decreased drug concentration variations

\section{Floating Microsphere Drawbacks}

$>$ Gastric mucosa irritants are often not appropriate for treatment

$>$ Need to float and function effectively with a high amount of stomach fluid for drug delivery

$>$ The central particle stability can be added by factors such as $\mathrm{pH}$ shift, temp, agitation.

$>$ In response to oxidation, hydrolysis and certain biological agents, the polymer can degrade

$>$ Not ideal for drugs with GIT solubility or stability issues

$>$ GIT-absorbed drugs that undergo first-pass metabolism may not be ideal.

\section{MECHANISM OF MICROSPHERE FLOATING}

They communicate with the acid in the stomach after administration of the dosage type, since the outer layer of the floating microspheres includes polysaccharides, polymer 
hydrates and forms a colloidal gel barrier that governs the movement of the drug and the gastric fluid in and out of the microspheres. The air molecule traps inside it because of this membrane, because it lowers its bulk density and lets it swim across the gastric fluid surface. For the floatation of the floating dosage type, a smaller amount of gastric fluid is required for maximum cases. Mechanism of drug release form microspheres following method .14,15
1. Erosion
2. Diffusion
3. Osmosis

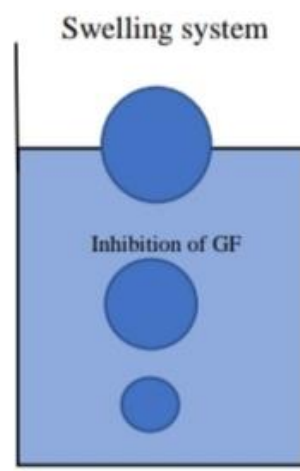

(A)

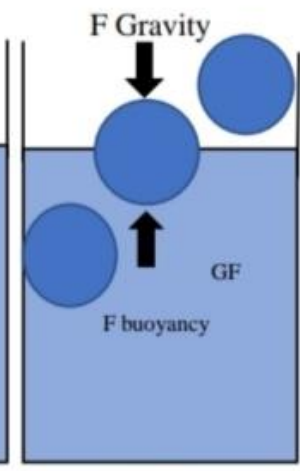

(B)
Gas generating system

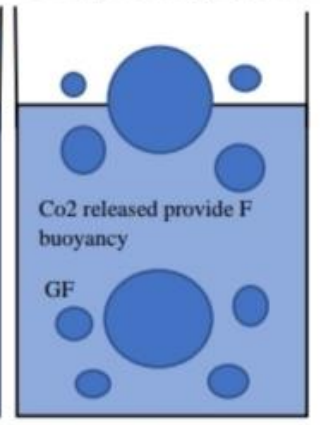

(C)

\section{TYPES OF MICROSPHERES}

1. Microspheres of Bio/ Muco-adhesive

2. Microspheres Magnetic

3. Microspheres Floating

4. Microspheres Radioactive

\section{Microspheres of Bio/ Muco-adhesive}

The expected or adhesion property of water-soluble polymer enables the microspheres to adhere to the walls of the mucosal layer or epithelial cell to the absorption site for the successful release drug as well as the therapeutic action. The epithelial or surface binding of polymers can be spilt into three categories $\mathbf{1 4 , 1 7}$.

- Hydration-mediated clinging.

- Adhesion-mediated by bonding.

- Adhesion mediated by receptors.

\section{Microspheres Magnetic}

The magnetic carrier that obtains magnetic response and works at target sites replaces free circulating medication. It is necessary that the drug be localized to the location of the disease ${ }^{18 .}$

\section{(a)Magnetic microspheres for therapeutics}

The delivery of chemotherapeutic agent to the liver tumour is included in this type of microsphere. It is also possible to target drugs such as proteins and peptides using this method.

\section{(b) Microspheres diagnostic}

This form of microsphere is used for imaging liver metastases and can also be used by producing nano-size particles of supramagnetic iron oxides to separate bowel loops from other belly structures.

\section{Microspheres Floating}

This form of drug intended for release with a fixed rate of high efficacy decreases the adverse effects and improves the bioavailability of the medication. A lasting appreciation of gastric ingredients is likely to be given by the floating drug delivery system. There are low swimming microspheres in which there is sufficient buoyancy in the float gastric material 19.

\section{Microspheres Radioactive}

Microspheres provide to the targeted areas a high dose of radiation without affecting the surrounding tissues. Radioactivity is not produced from microspheres but works from a standard distance inside a radioisotope and the different forms of radioactive microspheres are $\beta$ emitters, $\beta$ emitters, $\gamma$ emitters 20.

\section{Microspheres Polymeric}

\section{(a) Biodegradable microspheres of polymers}

They are biodegradable, biocompatible, and bio-adhesive natural polymers of this form as well. Due to its high degree of swelling property with aqueous medium, polymers with a spreading residence time when contact with the mucous membrane mark the gel forming process.

\section{(b) Polymeric synthetic microspheres}

Synthetic polymeric microspheres are widely used in clinical applications, and are often used as bulking agents, fillers, etc. 21

\section{PREPARATION PROCESS}

1. Technique for Single Emulsion

2. Technique of Double Emulsion

3. Coacervation technique of phase separation

4. Ionic process of gelation

5. Evaporating Solvent

6. Spray Drying

7. Diffusion of Quassi emulsion solvent

8. In this process, Wax Coating and Hot Melt

\section{Single Technique of Emulsion}

Natural polymers mostly use this form, i.e. the preparation of proteins and carbohydrates. Natural polymers are dispersed or dissolved in the aqueous medium and exhibit overdispersion in the non-aqueous medium with the help of linking agent alteration 22. 


\section{Double technique of emulsion}

In this method, the formation of more than one emulsion or double emulsion which consists of multiple emulsions, i.e. w/o/w. With natural polymers, mainly synthetic polymers and ideally suited for water-soluble drugs, peptides, proteins and vaccines, this process can be used. The primary emulsion then shows the effects of homogenization in the formation of a double emulsion 22 .

\section{Coacervation technique of phase separation}

It is based entirely on the organic part, reducing the polymer's solubility to affect the advancement of the polymer-rich phase known as coacervates. There are three phases; the covering polymer solution disperses one core material. Three non-miscible layer formation. The second is the polymer coating around the heart. Third, rigidization of the polymer coating by adding a cross-linking agent, desolvation of the thermal phase, using a non-aqueous vehicle, by salting out 23 .

\section{Ionic process of gelation}

In the distilled water, cross-linking agent and polymer were dissolved in this process to form a homogeneous polymer mixture. In order to form a smooth dispersion, medicine was applied to the polymer solution and thoroughly combined on a magnetic stirrer. Calcium chloride is a $2 \%$ glacial acetic acid-prepared cross-linker gelation medium. The syringe needle was used to extrude this coherent solution into the cross-linking solution. Microspheres are produced and then collected and washed twice with distilled water, and dried for 1 day at room temperature ${ }^{24,26}$.

\section{Evaporation Process of Solvent}

In a natural solvent, the polymer is dissolved and the medication is either dispersed or dissolved within the polymer solution. It then emulsified the required additive (surfactants/polymer) into an aqueous portion to form the emulsion of $\mathrm{o} / \mathrm{w}$. After creating a strong emulsion, the natural solvent is evaporated either by over-continuous stirring or by producing a strong emulsion.

\section{Methods for spray-drying}

Solid type of medication is obtained and then spread at higher speed in the polymer solution with homogenization \& material is accepted through the hot air stream that supports atom-level dispersion. This contributes to the growth of fine mist or tiny droplets. The effect is the formation of microspheres, which are then separated with the aid of hot air by the cyclone separator ${ }^{23,24}$.

\section{Method of Quasi emulsion liquid diffusion}

An outer phase containing purified water and polyvinyl alcohol is used in this process. Drugs, ethanol, and polymers are part of the internal process. The internal phase is produced initially at $60^{\circ} \mathrm{C}$ and then applied at room temperature to the external phase. The mixture is continuously stirred for 2 hours after the emulsification process. Then it is possible to filter the mixture for separation. The commodity is then washed and dried for a day at $40 \mathrm{oC}$ in a vacuum oven 22,23 .

\section{Coating Wax and Hot Melt}

Polymer is spread and slowly cooled in the required dispersion medium to form the microspheres. Low polymer melting point, invented in microspheres. Particle wax is often used for painting and coring. In which the drug is encapsulated in the molted wax by dispersion. The wax suspension is spread by high-speed cold solution mixing, e.g. liquid paraffin agitates $60 \mathrm{~min}$ mixtures 29

\section{EVALUATION OF FLOATING MICROSPHERES}

\section{Size of particles}

An optical microscopic approach has been used to determine the particle size of microspheres and the mean size of the microsphere was estimated using a calibrated ocular micrometre to measure 100 particles $^{\mathbf{2 8}}$.

\section{Density of Bulk}

Bulk density is defined as the powder mass divided by the density of the bulk. (Expressed in gm/cm3).

The Bulk Density = Sample Weight $/$ Sample Volume

\section{Density Tapped}

You may use the tapping approach to measure the densities tapped. After 100 taps as well as 1000 taps using tapped density apparatus, the volume of weighed quantities of microspheres was determined.

Tapped Density $=$ Sample Weight $/$ Volume Tapped

\section{Ratio of Hausner}

The index of compressibility and the Hausner ratio were determined from bulk density and tapped density values.

Compressibility Index percentage $=$ Tapped density- Bulk density/Tapped density

Hausner Ratio = Tapped Density / Bulk Density.

\section{Angle to Repose}

The resting angle of the microspheres, which calculates the resistance to particle flow, has been measured, $\tan \theta=h / r$

Where the angle of repose is, $\mathrm{h}$ is the pile height, $\mathrm{r}$ is the pile radius.

\section{Yield percentage}

The percentage yield of floating microspheres was determined by dividing the actual weight of the commodity into the total quantity of components used in floating microsphere preparation 26 .

$\%$ yield $=$ (Actual weight of product $/$ Total weight of drug and Excipients) $\times 100$

\section{Morphology of Surfaces}

Using the mixture of gold \& palladium at a thickness of 250 $450 \AA$ under an argon atmosphere in a high vacuum evaporator at a voltage of $20 \mathrm{KV}, 10 \mathrm{~mA} \&$ low pressure, the SEM sample was calculated by spreading the powder tap stuck involved to an aluminum stub coated content. Photomicrographs 28.

\section{Performance of drug entrapment efficiency (DEE)}

Estimated by repeated crushing of the microspheres and extraction with aliquots of $0.1 \mathrm{~N} \mathrm{HCl}$. The extract was transferred to a volumetric $100 \mathrm{ml}$ flask and $0.1 \mathrm{~N} \mathrm{HCl}$ was used to make up the volume. The solution was filtered and the absorbance measured against the blank by a spectrophotometer $\mathbf{2 5}$

Drug Entrapment percentage $=($ actual drug content/theoretical drug content) $\sim 10$ percent 


\section{Studies on swelling}

The analysis was performed by soaking the known weight of microspheres in $0.1 \mathrm{~N} \mathrm{HCl}$ at $37 \pm 0.5{ }^{\circ} \mathrm{C}$ for the appropriate time span. The microspheres are allowed to swell and are withdrawn at various intervals of time $\mathbf{2 7 .}$

Swelling Ratio $=$ Wet Formulation Weight / Formulation Weight

\section{Analysis of Buoyancy}

The microsphere was distributed above the surface of a type II USP dissolution apparatus filled with $0.1 \mathrm{~N} \mathrm{HCL} 900 \mathrm{ml}$ containing 0.02 percent between 80 and 20. The medium was stirred for $12 \mathrm{hrs}$ with a paddle spinning at $100 \mathrm{rpm}$. Separately, floating and settled parts of microspheres have been retrieved. They dried and measured the microspheres ${ }^{27}$.

Percentage buoyancy $=\mathrm{Wf} / \mathrm{Wf}+\mathrm{Ws} \times 100$

Where, Wf- Floating Weight, Ws-Settled Microsphere, respectively.

\section{Studies of in-vitro drug release}

In this analysis, USP dissolution devices were used at a specific speed. At $37 \pm 0.5^{\circ} \mathrm{C}$, distilled water and dissolution fluid are retained. The dissolution test is conducted using $900 \mathrm{~mL}$ of $0.1 \mathrm{~N}$ HCL dissolution medium at $100 \mathrm{rpm}$ for the time needed Samples removed at periodic intervals and samples substituted with the same quantity of fresh medium same for the maintenance of Spectrophotometrically analysed sink conditions $\mathbf{2 6}$.

\section{Evaluation In-Vivo}

It was used to initiate the dosage type place in the GIT tract and also to control the time of gastric emptying with its passage. X-rays may be used to view the invisible radio material used in the swimming microsphere. ${ }^{3}$

\section{FLOATING MICROSPHERE APPLICATIONS}

Due to the small absorption window in the top portion of the GIT, FDDS demonstrates numerous applications for drugs with low bioavailability $\mathbf{2 9 , 3 0}$

\section{Drug Delivery Sustained}

As a result, the bulk density is $<1$ and they can swim over the gastric material. The pyloric opening is prohibited by larger size and passing shape.

\section{Delivery of Site-Specific Drugs}

Via local drug release, floating microspheres can significantly enhance the pharmacotherapy of the abdomen, leading to high concentrations of medication in the gastric mucosa, thereby eradicating Helicobacter pylori from the submucosal tissue of the abdomen and to make it easier to treat gastritis, belly \& duodenal ulcers.

\section{Enhancement for Absorption}

Efficient in the delivery of medication that is sparingly soluble and insoluble. The solubility of a medication reduces, the time available for dissolution of the drug becomes less passable, and therefore the transit time becomes an essential factor influencing the absorption of the drug.

\section{As transporters}

These substances, antiviral, antifungal and antibiotic agents, used as carriers for medicinal products with so-called absorption windows, are only taken from very particular locations of the GI mucosa.

\section{Maintaining a constant blood level}

This device provides a convenient way to maintain a constant blood level, providing easy administration and improving patient compliance.

Table 1: Detailing of Medicaments used as Anti-ulcer Activity in the form of Floating Microsphere

\begin{tabular}{|c|c|c|c|c|c|c|}
\hline $\begin{array}{l}\text { Sr. } \\
\text { No }\end{array}$ & Medicament & Polymers & Method & Carrier & Disease & Ref \\
\hline 1 & Lafutidine & HPMCK4M & Ionotropic gelation method & Floating beds & Gastric ulcer & 31 \\
\hline 2 & Stavudine & Eudragit RS100, RL100 & Solvent evaporation method & Floating microsphere & Gastric ulcer & 32 \\
\hline 3 & Roxatidine & HPMC, ethyl cellulose & Solvent diffusion technique & Floating microsphere & Gastric ulcer & 33 \\
\hline 4 & Nimodipine & $\begin{array}{l}\text { Eudragit S 100, ethyl } \\
\text { cellulose }\end{array}$ & Solvent evaporation method & Floating microsphere & Gastric ulcer & 34 \\
\hline 5 & Cimetidine & HPMC, ethyl cellulose & Solvent evaporation method & Floating microsphere & Gastric ulcer & 35 \\
\hline 6 & Esomeprazole & $\begin{array}{l}\text { HPMC K4M, HPMC } \\
\text { K15M }\end{array}$ & $\begin{array}{l}\text { Double emulsion solvent } \\
\text { diffusion }\end{array}$ & Floating microsphere & Gastric ulcer & 36 \\
\hline 7 & Nizatidine & $\begin{array}{l}\text { Polymethyl } \\
\text { methacrylate }\end{array}$ & Solvent evaporation method & Floating microsphere & Gastric ulcer & 37 \\
\hline
\end{tabular}

\section{FUTURE PROSPECTIVES}

One of the key challenges in the pharmaceutical industry, notably for medicines that are absorbed from the upper part of the gut, is the GRT of the traditional dosage type. GRDDS development can help to address the disadvantages associated with traditional dosage type, although further work on its deficiencies is required. Although several GRDDS technologies have been widely studied to achieve an efficient gastro-retentive method. Future studies on GRDDS should therefore concentrate on combinations of various mechanisms with a view to prolonging the gastric residences time of formulation even when under fasting conditions. On a case-by-case basis, it is essential to evaluate gastroretentive dosage forms because the physiochemical existence of drugs and excipients, polymer types and structure, drug dose, and manufacturability can rely on product specification. Knowing the impact of formulation and process variables on the essential quality attributes of GRDDS is another important factor for improving GRDDS. From the point of view of 
formulation, it is important for the logical production of the gastroretentive dosage type to understand polymer behavior and its role in formulation. In addition, the choice of the required polymer concentration is equally critical for the design of such a dosage type. In addition, for the design of such dosage forms, the selection of an appropriate polymer concentration is equally critical. In this regard, the approach to quality by design (QbD) can be a useful method to investigate the effect of variables in formulation and process on the essential quality attributes of GRDDS. There has been a big shift in the understanding and regulation of the manufacturing process with the introduction of the QbD method in the pharmaceutical sector, which notably minimizes the risk of product failure. $\mathbf{3 8 , 3 9}$

\section{CONCLUSION}

As a competent strategy for increasing bioavailability and regulated delivery of various beneficial agents, floating microspheres have emerged. Major worldwide efforts have been made to discover these systems, both in terms of therapeutic efficacy and compliance, which meet patient needs. As gastro retentive dosage types, floating microspheres moderately regulate the release rate of target drug to a particular site and promote a vast effect on health care. In the working management of many diseases, optimized multi-unit floating microspheres are expected to give clinicians with a new option of an affordable, healthy and extra bioavailable formulation. These systems also offer great examples of manipulating new controlled and late release oral formulations, thereby encompassing the frontier of revolutionary pharmaceutical production. Improved strain of this device will ensure efficient gastro retentive microspheres therapy improvements in the street in order to maximize the distribution of molecules in a more informed way.

\section{REFERENCES}

1. Abdul H, Arun M, Jagpal S, Ankit M, Lakhan R. An overview on Floating Microsphere: Gastro Retention Floating drug delivery system (FDDS).The Journal of Phytopharmacology. 2013; 2(3):112.

2. Mirmeera GN, Kannan K, Madhukar. A Overview on Floating drug delivery system. International Journal of Applied Pharmaceutics. 2018; 10(6):66-70.

3. Lalit K, Abhishek S. Gastro Retentive Floating Microsphere: A Review. Journal of Pharmaceutical Sciences \& Bioscientific Research. 2019; 9(2):142-148.

4. Shinde TS, Barathe AN. A Review on Floating Microsphere. Journal of Pharmaceutical and Biological Sciences Archive.2019; 7(3):87-92.

5. Radha R, Manish K, Narendra Y, Shailendra B, Anuj M, Beena K, Sangeeta D, Anil K. Recent Advances In the Development of Floating Microspheres for the Treatment of Gastric Ulcers. International Journal of Advanced Sciences and Technology.2020; 29(5):3613-3627

6. Sonia N, Johan W, I, Kumaran J, Aprana P, Jaghatha T.A. Review on Floating drug delivery system. Word Journal of Pharmaceutical and Medical Research.2018; 4(5):275-281.

7. Satyajit P, Priyanka K, R Varaprasad, Snigdha P. Gatroretentive Microsphere: An Innovative Approach for prolonging Gastric Residence. International Journal of Drug Delivery Technology.2019; 9(1):1-9.

8. Swapnil M, Kaustubh G, Onkar D, Prasad K. Gatroretentive Drug Delivery System. Journal of Drug Delivery \& Therapeutics. 2018; 8(4):24-35. DOI https://doi.org/10.22270/jddt.v8i4.1788

9. Shailaja P, Ashutosh B, Preeti k. A review on Gastroretentive drug delivery System. International Journal of Research and Development in Pharmacy and Life Sciences. 2016; 5:21782187.

10. Amit KN, Ruma M, Biswarup D. Gastroretentive Drug Delivery System: A review. Asian Journal of Pharmaceutical and Clinical Research. 2010; 3(1):2-10.
11. Shaikh S, Molvi KI, Sayyed N. Various perspectives of Gastroretentive drug delivery System: A Review. American Journal of Advanced Drug Delivery. 2013; 1:443-451.

12. Ankur RS and Afroz K, Gastroretentive drug delivery system: An Approach to Enhance Gastric Retention for Prolonged Drug Release. International Journal of Pharmaceutical Sciences and Research. 2014; 5(4):1095-1106.

13. Nilesh K, Mukta K, Jyoti R, Shashikant ND. Formulation \& Evaluation of Gatroretentive Floating Microsphere: A systematic review. International Journal of Pharmaceutical Sciences \& Research. 2020; 11(1):1000-13.

14. Gholap SB, Banarjee SK, Gaikwad DD, Jadhav SL, Thorat RM. Hallow Microsphere. International Journal of Pharmaceutical Sciences Review and Research. 2010; 1(1):74-79.

15. Shaikh SZ, Shahid M. Floating tablet \& its polymer. Journal of Drug Delivery \& Therapeutics. 2018; 8(5-s):16-24. DOI https://doi.org/10.22270/jddt.v8i5-s.1928

16. Gayathridevi MJ. Adlin Jino Nesalin and T. Tamizh Mani. Floating Microsphere: A Review. International Journal of Research in Pharmacy and Chemistry. 2016; 6(3):501-510.

17. Deshmukh M.T, Mohite S.K. Mucoadhesive Microsphere as a Drug Delivery System: A Review. Journal of Current Pharmaceutical Research. 2015; 5(3):1505-1512.

18. Satinder K, Deep B, Ramandeep S, Ujjwal N. Magnetic Microsphere as Magical Novel Drug Delivery System: A review. Journal of Acute Disease. 2013; 2(1):1-12.

19. Iyan S, Sriwidodo, Retno, Wahyuningrum, Norsca Aliza P. A review: Floating drug delivery system as tool to Improve dissolution rate in gastric. International Journal of Applied Pharmaceutics. 2020; 12(4):51-54.

20. Manisha M, Saudagar R B. Microsphere A review. Journal of Drug Delivery and Therapeutics. 2019; 9(3-s):854-856. DOI https://doi.org/10.22270/jddt.v9i3-s.2826

21. Tarun V and Jyoti G. Pharmaceutical Application of Microsphere: an approach for the treatment of various disease. International Journal of Pharmaceutical Sciences \& Research. 2017; 8(8):3252-3260.

22. Swati M. Aute, Santosh A. Payghan, John I. D’Souza, Smita Navhkar, Dhanshree Lad, Umesh Jirole. Novel Approach in Gastro Retentive Drug Delivery System: Floating microsphere. International Journal of Pharmacy and Biological Sciences Archive. 2014; 2(5):09-22.

23. Anamika S, Kalpesh G, Virendra S, Rajneesh KS, and Ashok D Floating Microspheres as Drug Delivery System. American Journal of Pharmacy and Pharmaceutical Sciences. 2014; 1(2):27-36.

24. Ishwaryal M, Ramu S, Saravana K. Floating Microspheres: A Promising Drug Delivery. International Journal of Pharmacy \& Pharmaceutical Research. 2017; 11(1):375-388.

25. Koteswararao SR, Srinivas L. A Review on Multi-Particulate Floating Microspheres Drug Delivery System with Solvent Evaporation Approach. Int J of Pharm Res and Health Sci. 2018; 6(3):2570-78.

26. Rakesh P, Neeta, Shiv B. Vipin K and Kanchan K. Floating Microsphere: An Innovative Approaches for Gastric retention: Der Pharmacia Lettere. 2010; 2(4):461-475.

27. Kapil K, Rai AK. Floating Microsphere: An Innovative Approach for Gastro retention. J of Pharm Res. 2012; 5(2):883-886.

28. Gandhi S, Dadi S, Ramesh J, Kalyani V, Nagamma I. Floating Microspheres: A Prevailing Trend in the Development of Gastroretentive Drug Delivery System. Asian J of Pharm. 2018; 12(4):235-241.

29. Vishakha RJ, Swapnil RP, Tushar DF. A Review on: Floating Microsphere. American Journal of Pharmaceutical Technique Research. 2020; 10 (2):231-258.

30. Aundumber D, Ritesh SB, Manoj K P. Floating Microsphere: A Novel Approach in Drug Delivery System. GCC J of Sciences \& Technology. 2015; 1(5):134-153.

31. Kumar R, Kumar P, Chandra S, Formulation and Evaluation of Multiple Unit Floating Beads of Antiulcer Drug. Asian Journal of Pharmacy. 2018; 12(2):680-689.

32. Sahoo SK, Mallick AA, Barik. Formulation and in-vitro evaluation of eudragit $®$ Microspheres of stavudine. Tropical Journal of Pharmaceutical Sciences. 2005; 4:369-75.

33. Miranda FC, Kamanth KK, Shabarya AR. Development of gastro retentive floating microsphere of roxatidine acetate HCL by emulsion solvent diffusion technique. International Journal of Diabetes in Developing Countries. 2019; 9(4)531-537. 
34. Swetha K, Madhavi HS, Vasudha B. Formulation and Evaluation of Gastro Retentive Floating Microsphere of Nimodipine. Asian Journal of Pharmacy. 2016; 10:628-635.

35. Srivatava, AK, Ridhurkar DN, Saurabh W. Floating Microspheres of Cimetidine: Formulation, Characterization and In Vitro evaluation. Acta Pharmaceutical. 2005; 55:277-285.

36. Prakash G, Shashikanth R. Development and in vitro characterization of esomeprazole floating gastro retentive Microsphere. Journal of applied Pharmaceutical Sciences. 2013; 3:71-77.
37. Sanjay KM, Gupta MK. Characterization and Evaluation of Nizatidine Floating Microsphere based drug delivery system for antiulcer activity. International Journal of Pharmaceutical Sciences \& Research.2019; 10:4557-4567.

38. Prinderre, P, Sauzet, C, Fuxen, C. Advances in gastro retentive drug-delivery systems. Expert Opin. Drug Delivery.2011; 8: 1189-1203.

39. Thapa, P, Jeong, S. Effects of Formulation and Process Variables on Gastroretentive Floating Tablets with A High-Dose Soluble Drug and Experimental Design Approach. Pharmaceutics.2018; 10:1-25. 